\title{
Tradable white certificate schemes: what can we learn from tradable green certificate schemes?
}

\author{
Vlasis Oikonomou • Luis Mundaca
}

Received: 24 May 2007 / Accepted: 5 June 2008 /Published online: 12 July 2008

(C) The Author(s) 2008

\begin{abstract}
In this paper, we analyze the experiences gained from tradable green certificate (TGC) schemes and extract some policy lessons that can lead to a successful design of a market-based approach for energy efficiency improvement, alias tradable white certificate schemes. We use tradable green certificate schemes existing in the Netherlands and Sweden as case studies. Departing from an assessment of both TGC schemes, we identify several institutional and market aspects that have affected their performance. We conduct the analysis by addressing key evaluation criteria (i.e., cost and energy effectiveness, administrative burden, technological innovation, political feasibility, and transaction costs). It is not our intention to demonstrate to the reader a normative aspect of designing tradable white certificate schemes. Rather, we identify some key policy lessons which
\end{abstract}

\footnotetext{
V. Oikonomou $(\bowtie)$

Department of Economics, University of Groningen, P.O. Box 800, 9700 Av,

Groningen, the Netherlands

e-mail: v.oikonomou@rug.nl

L. Mundaca

International Institute for Industrial Environmental

Economics, Lund University,

P.O. Box 196, 22100 Lund, Sweden
}

can be summarized as: a binding long-term target must be clearly expressed in terms of policy time frame and certainty, a proper liquid market must be ensured for tradability of certificates, the scheme should be technology neutral, transaction costs should be kept low, and the energy efficiency target should not only address 'low hanging fruits' but also promote innovation.

Keywords Tradable green certificates - Tradable white certificates $\cdot$ Renewable energy $\cdot$ Energy efficiency

\section{Introduction}

In environmental and energy policy arenas, several traditional policy instruments address various issues and targets. In the last years, there is an increasing interest in market-based economic instruments, namely, tradable certificates. The main argument for implementing tradable certificate schemes is that they can take full advantage of market forces and its agents to work in favor of the environment (Portney 2003). By reducing the costs of obligated parties to achieve their target, such schemes have largely attracted the attention of policy makers.

Lately, more attention gains the role of tradable certificates as a policy instrument to increase energy 
efficiency above business-as-usual level. At European Union (EU) level, the Directive on energy end-use efficiency and energy services aims at enhancing the efficient end-use of energy in EU by removing barriers that obstruct the realization of greater energy efficiency (EC 2006a). This Directive suggests a nonbinding $9 \%$ energy efficiency improvement spread over 9 years and encourages several policy instruments to achieve its goal. Finally, the EU Action Plan for energy efficiency sets much higher targets at the level of $20 \%$ energy efficiency improvement by 2020, almost 390 million tons of oil equivalent saved, given the existing potential for such actions (EC 2006b). For European policy makers, the implementation of tradable white certificates (TWC) as marketbased instrument aiming at encouraging greater energy efficiency is gaining attention and currently many research initiatives are underway assisting that policy process.

Another similar market-based policy instrument addressing the deployment of renewable energy (RE) production and technologies is the tradable green certificates (TGC). TGC have become an increasingly common instrument for RE targets in OECD countries (Australia, Belgium, UK, the Netherlands, Sweden) with different design characteristics and specific targets. The EU Directive on the promotion of electricity produced from renewable energy sources in the internal electricity market (EC 2001) also strongly supports TGC schemes. They are mostly included in Renewable Portfolio Standards in contrast to traditional feed-in tariffs.

The EU SAVE project 'A Comparison of Market Mechanisms for Energy Efficiency' (so-called 'White and Green' project) partially explored the suitability and effectiveness of TWC schemes. ${ }^{1}$ Based on the quantitative results from modeling work for the case of western Europe (Mundaca and Santi 2004), implementation of TWC yields cost-effective energy savings and reductions of $\mathrm{CO}_{2}$ emissions as a result of higher penetration of more efficient technologies in the residential and commercial service sector. The order of magnitude of these effects depends on the design and target applied. Findings of this study are

\footnotetext{
${ }^{1}$ For further information about the "White and Green" project visit: http://www.iiiee.lu.se/whiteandgreen.
}

only a departure point for further analyses. In fact, critical assessments of issues such as transaction costs, administrative burden, and acceptability of these schemes-among others-remain to tackle. The combination of these research elements can provide a more comprehensive analysis and evaluation of TWC schemes in order to provide views regarding the fundamental policy question: Are TWC schemes a right policy choice?

In this paper, departing from TGC schemes that are at place for more than 5 years in EU countries, we make use of these experiences and draw lessons for designing and implementing TWC schemes. Initially, we attempt to evaluate TGC schemes according to key policy criteria. Based on key and common elements among schemes that have influenced the performance of TGC schemes in Sweden and in the Netherlands, this paper draws lessons that can be taken into consideration in order to improve the performance of current or planned TWC schemes. The choice of Sweden and the Netherlands is because both countries have mature renewable energy markets and substantial experience with energy policy and market-based policy approaches. As an outcome of this paper, we extract the most important positive and negative effects of TGC that were due to their initial design and extrapolate them to similar design parameters that determine the outcome of future TWC schemes.

The structure of this paper has as follows. In "Analytical framework" section, we present the method of comparison we use in our analysis. "White certificate schemes: an overview" section consists of an overview of TWC schemes with a short description of their main characteristics in the countries already implemented. "Green certificate schemes" section deals with green certificate schemes and their evolution in the Netherlands and Sweden, alongside with some cross comparisons of their characteristics. Furthermore, the next section ("Lessons from the Dutch and Swedish TGC schemes") refers exclusively to an evaluation of both schemes based on specific criteria. In "Discussion" section, we extrapolate lessons learned from these schemes that can be relevant for TWC schemes. We identify main design characteristics of TWC that need special attention and provide some recommendations for policymakers. Finally, "Conclusions" section is a wrap up of the whole paper highlighting the most important findings. 


\section{Analytical framework}

The method we employ in this paper to extract results from TGC for TWC schemes consists of three steps ${ }^{2}$. Initially, we identify basic characteristics of TGC schemes that address their design features. At a second step, we select criteria from the same study (beyond effectiveness and efficiency), reveal relationships between criteria and design characteristics, and evaluate the performance of TGC schemes based on these criteria. Finally, we extrapolate these design characteristics to TWC schemes and based on the relationships of the previous step we extract some policy lessons.

\section{White certificate schemes: an overview}

TWC is a relatively new policy instrument in the field of energy efficiency. Its basic idea is that energy suppliers or distributors must fulfil specific energy saving targets by implementing energy efficiency measures towards their clients within a specific time frame. Energy suppliers or distributors that save more energy than their targets can sell these surplus energy efficiency equivalents in the form of TWC to suppliers/distributors that cannot fulfil their targets. Currently, there are three TWC schemes in place: in Italy, France, and the UK, while other countries are considering their implementation (e.g., Poland, the Netherlands). In general, the rational of implementing TWC schemes targets is at the following:

- Improving energy efficiency and reducing energy intensity in the economy

- Securing energy supply and at a much lesser extent fulfilling Kyoto Protocol requirements

\footnotetext{
$\overline{2}$ This method is a fragment of a study by Oikonomou and Jepma (2008) and its application in Oikonomou and van der Gaast (2008). A basic difference is that in this paper, we do not refer to the policy interactions part. This study gained some attention and evolved into the Energy and Climate Policy Interaction Decision Support Tool. More information and reports are present in the tool's web page (http://www.rug.nl/ edrec). An analytic documentation of the functioning of the tool with the relationships of criteria with design characteristics can be found in Oikonomou et al (2008). Moreover, the EU SAVE 'White and Green' project has employed the same method of analyzing TGC and TWC policy instruments.
}

- Compliance with requirements to certify an attribute (energy efficiency), which is a volatile and hardly measurable entity, rather than a quantity. In fact, leaving aside the question of "trading", a TWC scheme is in itself a valid mechanism for formalizing official quantification and endorsement of energy savings

- New opportunities within an already existing and more general "environmental market", including green certificates and emission trading

- Wide public consent/approval, due to the related image, connected to energy savings and environmental issues

A TWC scheme in its design phase consists of the following elements upon which decisions are taken (International Energy Agency 2006): (a) target setting, (b) obliged parties, (c) counting target upgrading, (d) compliance, transaction, and administrative costs, (e) eligible technologies, (f) institutional setup, (g) enforcement, (h) trading rules, and (i) links to other policy instruments. Relevant information can be found in a growing literature (EU SAVE "White and Green" project; EuroWhiteCert project; Farinelli et al. 2005; Bertoldi and Rezessy 2006; International Energy Agency 2006; Langniss and Praetorius 2006; Oikonomou et al. 2007a; Mundaca 2007). Target setting refers to the level of obligation, expressed in TWh or ton of oil equivalent saved. Another aspect of this characteristic is the time frame upon which obligated parties must fulfil the target. Obliged parties are market entities that receive the obligation and are, namely, energy suppliers, energy distributors, and/or energy consumers. Counting target upgrading comprises the framework upon which energy savings are recognized as eligible to count against the target set-with due analysis of remaining energy efficiency potentials. These rules require the establishment of a monitoring and verification system that confirms eligible energy savings from actions of obligated parties. Compliance costs are direct costs carried over by obligated parties - but eventually transferred to end users via energy tariffs - when implementing energy efficiency projects to end users and are also determined by the market of TWC, which in theory should reflect shadow costs of these projects. Transaction costs (e.g., search for information, negotiation with trading partners, due diligence, etc.) do not only relate to trading and redemption of TWC but are also 
apparent during planning, implementation, and verification phase of eligible energy efficiency measures (Mundaca and Neij 2006). Finally, administration costs refer to costs from public bodies that are required in order to design, implement, and enforce the scheme. ${ }^{3}$ Eligible technologies are the choices of specific technologies and packages of measures allowed and recognized as appropriate for counting against the target. Institutional setup consists of the choice of entities that undertake setting up, administration, verification, registration, and reporting requirements of a TWC scheme. Trading rules refer to a framework upon which trading of TWC can take place and include arrangements for managing supply and demand of certificates and design characteristics of certificates. Enforcement deals with sanctions and penalties that suppliers must pay in case they cannot comply with their obligations. Links to other instruments are interactions of TWC schemes with other existing or planned policy instruments that address similar targets and sectors (e.g., performance requirement for appliances).

Table 1 summarizes the general characteristics that policy makers keep in mind when designing a TWC scheme alongside with dilemmas and questions they are facing. These questions are approached differently in countries with TWC schemes. Although the nature of any tradable certificate scheme is common (i.e., equalize compliance marginal costs among responsible parties), one can easily notice that there is no specific or standard design of these schemes.

\section{Green certificate schemes}

In this section, we analyze characteristics of TGC schemes already in place in the Netherlands and Sweden. A green certificate actually represents the "greenness" of a unit of RE production. This divides the unit in two parts: the physical electricity and its associated "greenness", which can be traded in two different markets, and the conventional physical electricity markets and a market for certificates (Mitchell and Anderson 2000). Primary targets addressed by TGC schemes are the reduction of oil dependence, Kyoto Protocol commitments (reduction

\footnotetext{
${ }^{3}$ Notice that administrative costs can also be considered as a source of transaction costs for obliged parties (Mundaca 2007).
}

of greenhouse gas (GHG) emissions), security of energy supply, and diversification of RE sources. The hierarchy of these targets can vary at some extent on national energy market characteristics and incumbent industrial structures.

A system of TGC belongs mainly to the category of regulatory instruments, which aids public authorities to reach a specific goal of RE production by putting in practice advantages of the market, and as an accounting system that certifies RE production. A basic distinction is made between the mandatory or voluntary character of demand for TGC. They can be considered as a regulatory instrument for long-term wider use of RE only if demand is set and mandatory.

Supply of certificates is achieved when producers of RE sell the units to the grid and acquire TGC. Demand for certificates is induced by transferring the national target for $\mathrm{RE}$ to either consumers or to distribution companies. The obligation can be set to any points of the electricity supply chain, from production to consumption. The most known obligation schemes apply to production, distribution, and consumption, where the latter are preferable to other schemes, as it is argued that they are more consistent with market liberalization principles (Schaeffer et al. 2000). In the following sections, we canvass the implementation of TGC schemes at stake into the general policy framework (i.e., other interacting policy instruments) in the Netherlands and Sweden.

\section{The Dutch TGC scheme}

The system of green certificates in the Netherlands has undergone three phases, linked with parallel taxation and other policies in each period. In 19982000 , the RE quota scheme was functioning under green labels originating from the voluntary agreements from distribution companies, in accordance with the Environmental Action Plan (EAP; 2000). The target set was $1,700 \mathrm{GWh}$ RE supplied to consumers, representing the $3.2 \%$ of total electricity. It was split among distributors, according to their sales volume. Distribution companies could purchase tradable green labels from producers or from other distributors who had fulfilled their target, while a sanction was imposed for not reaching the target. Parallel instruments at place were a feed in tariff (1989 Electricity Act), investment, and production incentives, a voluntary depreciation on investments 
Table 1 Issues in white certificates setting

\begin{tabular}{|c|c|}
\hline Characteristics & Questions raised \\
\hline Target setting & What should be the target? What is the specific timeframe? \\
\hline Obliged parties & $\begin{array}{l}\text { Which market party should undertake the obligation? Are there other } \\
\text { eligible parties? Does the scheme enhance competition or does it } \\
\text { lead to market concentration? }\end{array}$ \\
\hline Counting rules & $\begin{array}{l}\text { Which projects are eligible for certification? Sales or end-use counts } \\
\text { for target? Are there verification requirements? }\end{array}$ \\
\hline Costs & $\begin{array}{l}\text { Compliance costs? TWC costs? Transaction costs? Administrative } \\
\text { costs? Does learning reduce such costs? Do costs reflect energy } \\
\text { efficiency costs? Are there dangers for gold plating? }\end{array}$ \\
\hline Eligible technologies & $\begin{array}{l}\text { Are all or specific technologies allowed? Does the scheme support } \\
\text { innovation or advantages existing technology diffusion? }\end{array}$ \\
\hline Institutional setup & $\begin{array}{l}\text { Which body undertakes these costs? Which body is responsible for } \\
\text { which procedures? Are there possible conflicts between procedures? }\end{array}$ \\
\hline Trading rules & $\begin{array}{l}\text { Is trading prerequisite for the scheme? How can the scheme enhance } \\
\text { trading? }\end{array}$ \\
\hline Enforcement & $\begin{array}{l}\text { What is the optimal level of penalty? Is the penalty relevant to sales } \\
\text { or not covered target? }\end{array}$ \\
\hline Links to other instruments & $\begin{array}{l}\text { Complementarities and overlaps with other instruments? Timing of } \\
\text { instruments? }\end{array}$ \\
\hline
\end{tabular}

scheme (1996), and a green funding program in 1995 (Agnolucci 2007). The pricing mechanism of green labels scheme consisted of: (a) a small feed-in price (3.2-3.8 €/kWh), (b) the green label price $(2 € / \mathrm{kWh})$, and (c) a production subsidy rose from the energy tax on consumers $(1.9 € / \mathrm{kWh})$. The penalty was set around $3 € / \mathrm{kWh}$. Consumers on a voluntary basis were paying an extra price for the RE, while imported $\mathrm{RE}$ could receive green labels.

The second phase of the scheme (2000-2003) involved green certificates, also on voluntary basis. Producers of RE could achieve a reduction in their Regulatory Energy Tax (REB) ${ }^{4}$, while RE consumers were completely exempted from the tax. This resulted in the reduction of price difference of RE with conventional electricity, where in some cases, this price difference for consumers was zero (van Rooijen and van Wees 2006). The tax exemption was applied only with the actual consumption of RE, not just through issuance. Participation in the TGC market could not coincide with a financial support originating from EAP subsidies. An innovative policy in the Netherlands

\footnotetext{
${ }^{4}$ The Regulatory Energy Tax is an energy levy on electricity and gas consumption imposed on small and medium-size customers.
}

was the combination of TGC with fiscal measures and a fully liberalized market for green electricity. In 2002 , the total support for RE amounted to $8 € / \mathrm{kWh}$, which consisted of $6 € / \mathrm{kWh}$ (REB exemption) and $2 € / \mathrm{kWh}$ production subsidy (van Alphen and Pfeiffer 2005). The indicative RE target was $6 \%$ of total electricity used, $9 \%$ of the electricity to be stimulated by RE by 2010 , and $17 \%$ produced RE by 2020 . In 2003, the milieukwaliteits electriciteitproduktie (MEP) came into force ${ }^{5}$, which allowed subsidization only to domestic production. However, this support gradually ceased by 2005 . The MEP tariff provided initially max $7 € \mathrm{c} / \mathrm{kWh}$ and it differed according to RE technologies and sources (van Sambeek and van Thuijl 2003). TGCs had various sizes, all multiple of one MWh $(1,10,100,1,000,10,000)$, in order to reduce the administrative burden, and were valid for 1 year. Certificate prices, hence, were determined by the level of the REB exemption and the competition from foreign sources. The certification included periodical approval, the greenness of electricity, and the reliability of administrative process.

\footnotetext{
${ }^{5}$ The MEP is a kWh subsidy paid to domestic producers of electricity from renewable sources and CHP who feed-in to the national grid. The State guarantees the subsidy for a maximum of 10 years, though not for CHP.
} 
In 2004, the implementation of the EU Directive on the promotion of electricity produced from renewable energy sources in the internal electricity market (EC 2001) led to the continuation of the TGC scheme with Guarantees of Origin (GoOs). This voluntary scheme functions parallel to a system of labeling of electricity, which obliges energy suppliers to inform their customers of the origin of energy sold. In the meantime, the zero tariff for final users is abolished in phases in the beginning of 2005, in order to stop the fiscal incentive of importing RE. The Dutch government has appointed Certiq as an official issuance and monitoring body for the GoOs scheme ${ }^{6}$. There are two types of GoOs: those that can apply for REB (tax exemption based on production method: wind turbines, biomass plants including waste incinerators, solar, and hydropower plants) and those that do not, but both are valid for 1 year (van Alphen and Pfeiffer 2005). Under the GoOs scheme, imported RE is allowed and respective GoOs are redeemed. Furthermore, GoOs are available for sale after the producers have received income out of selling corresponding electricity and out of subsidy (RECS 2005).

All these schemes led to a rapid increase in the number of RE consumers domestically. The high number of consumers is uncertain if it remains the same, since also the market of conventional electricity opens. However, in the near future, the EU aims at establishing obligation systems, where producers, consumers, or suppliers need to consume, produce, and supply a minimum RE (Dijk et al. 2003). For the Netherlands, a limited subsidy will address projects under tendering procedure. With the increase of MEP and abolishing of REB exemption, the total level of support is still balanced and remains in the same level. However, the abolishment of REB exemption must be raised in accordance with the value of RE in Europe. The REB exemption targets both the producers and suppliers of RE, while the MEP targets exclusively to producers (van Sambeek and van Thuijl 2003). The abolishment of REB, therefore, will improve the security of investments for producers. Table 2 presents a breakdown of the Dutch

\footnotetext{
${ }^{6}$ Certiq is a daughter company of the national TSO, TenneT.
}

TGC according to design parameters and responsible bodies that participated in the scheme.

As a conclusive remark, the Dutch TGC scheme presented in general very positive in terms of effectiveness, while efforts to improve the fallacies and bottlenecks were undertaken. A more detailed evaluation according to criteria set follows in a next section of this paper.

\section{The Swedish TGC scheme}

Sweden's energy policy targets aim at creating conditions for ensuring security of supply, increasing efficient use of energy, and encouraging a costefficient Swedish supply of energy in parallel with minimum effects on health, environment, and climate (STEM 2005c). There is also the intention to secure energy supply and reduce GHG emissions through the promotion of RE. The latter one finally depends on the type of fuel that is replaced by RE and the level of ambition of the scheme. ${ }^{7}$ The promotion of RE via TGC aims at supporting to achieve the Swedish Kyoto target (i.e., mean value of $4 \%$ by $2008-2012$ compared to 1990 levels; STEM and Swedish EPA 2004). The introduction of TGC scheme also came to support the European Directive on RE (EC 2001), with Sweden having an indicative target of $60 \%$ by 2010 .

Sweden announced the introduction of TGC in 2002 through an energy policy declaration proposed by the Government to the Parliament (Riksdagen). The TGC in Sweden was officially introduced by the 'Electricity Certificate Act' (Lag om elcertifikat SFS 2003:113) in 2003. The main elements of the Act concerns the promotion of electricity generated from RE sources and the definition of eligible producers that can obtain certificates under the scheme. It obliges all end users of electricity regardless of its source-with the exception of energy intensive industries - to acquire TGC corresponding to a certain proportion of their electricity use. The ambition level is to achieve 17 TWh by 2016. A quota obligation was created then to trigger the demand for RE. This quota obligation varies on a year basis (see "Energy

\footnotetext{
${ }^{7}$ Nevertheless, the RE targets in Sweden do not have the same significance in GHG reduction, as in other countries, due to the fact that the majority of supplied energy originates from nuclear and hydropower (Wang 2006).
} 
Table 2 Key features of the Dutch tradable green certificates scheme

\footnotetext{
${ }^{\mathrm{a}}$ Tweede Kamer, vergaderjaar 2001-2002, 28 272, no. 1-2 taken from Tweede Kamer der StatenGeneraal, 29630, Groene Stroom
}

Dutch TGC scheme: 1998-2000, 2000-2003, 2003-...

\begin{tabular}{|c|c|}
\hline Obliged parties & Distributors, second phase producers ( + traders, aggregators) \\
\hline Compliance period & $\begin{array}{l}1998-2000 \text { (green label), 2000-2003 (green certificates), } \\
2003-\ldots \text { (GoOs) }\end{array}$ \\
\hline Obligation & $3,2 \%(1,700 \mathrm{GWh})$, then $6 \%$, and finally $9 \%$ in 2010 and $17 \%$ in 2020 \\
\hline Reference & Energy sales to consumers \\
\hline Criteria & Progressively tighter for companies of increasing capacity \\
\hline Eligible technologies & $\begin{array}{l}\text { Biomass, hydropower production }(<15 \mathrm{MWh}) \text {, solar, wave tidal, wind. } \\
\text { For CHP production, nontradable CHP certificates are issued }\end{array}$ \\
\hline Project evaluation & $\begin{array}{l}\text { Green Declaration by the registered producer. The regional grid } \\
\text { administrator dispatches metering data to the certificate system }\end{array}$ \\
\hline Certificates & $\begin{array}{l}\text { Green labels, then green certificates (valid for } 1 \text { year), and now GoOs } \\
\text { tradable and nontradable (e.g., CHP certificates cannot be traded) }\end{array}$ \\
\hline Trading parties & Energy distributors, producers and traders \\
\hline Penalty & $\begin{array}{l}50 \% \text { above the average market price of the green labels }(3 € / \mathrm{kWh}) \\
\text { currently none }\end{array}$ \\
\hline \multirow[t]{3}{*}{ Scheme financing } & $\begin{array}{l}\text { 1998-2000: Feed-in price }(3,2-3,8 € / \mathrm{kWh}) \text {, green label price }(2 € / \mathrm{kWh}) \\
\text { and production subsidy from the consumers energy tax }(1.9 € / \mathrm{kWh})\end{array}$ \\
\hline & $\begin{array}{l}\text { 2000-2003: REB reduction ( } 6 € / \mathrm{kWh} \text { only after the actual consumption } \\
\text { of RE, not just issuance of certificates), production subsidy }(2 € / \mathrm{kWh}) \\
\text { and from } 2003 \text { MEP comes into force }\end{array}$ \\
\hline & 2003-...: REB exemption abolished, MEP increased \\
\hline Total system costs & 2.7 billion $€(1999-2007)$ \\
\hline Targets achieved & $\begin{array}{l}2.2 \text { million RE consumers ( } 32 \% \text { of the total in } 2003 \text { ) but still uncertain } \\
\text { for } 2010^{\mathrm{a}}\end{array}$ \\
\hline System administrator & Tennet, -Enerq (request and grant $M E P$ )- \\
\hline Issuing body & 1998-2000: Green Certificates Body, 2001-.. Certiq \\
\hline Monitoring & Dte, Tennet, Belastingdienst (until 2005), Ministry of Economics, Certiq \\
\hline \multicolumn{2}{|l|}{ Verification } \\
\hline Registration & 1998:2000: National Treasury, 2001-... Certiq \\
\hline
\end{tabular}

effectiveness" section for further details). In 2006 for instance, obliged parties had to purchase $12.6 \%$ of electricity use. Types of RE technologies that are eligible for gaining certification are:

1. Wind power

2. Solar energy

3. Geothermal energy

4. Biofuels, including peat (in CHP plants), biogas, and landfill gas since April 2004

5. Wave and tidal energy

6. Hydro power:

- Smaller plants - units with installed capacity up to $1,500 \mathrm{~kW}-$

- Increase of production from existing plantsunits $>1,500 \mathrm{~kW}-$

- New plants
Lately, the Swedish TGC scheme has been subject to major design modifications in order to enhance its performance. $^{8}$ In June 2006, the Swedish Parliament made several decisions that came into force in

\footnotetext{
${ }^{8}$ Notice that Sweden established a system of Guarantees of Origin (GoOs) in a dual form: GoOs issued parallel to TGC, which are not tradable, and GoOs issued for other RE sources independent of TGC. We will not refer in depth to this scheme in this paper, since it is under modification and there are plans to adapt the trading of GoOs and TGC alongside with their redemption period. In fact, GoOs are delivered to producers, whose amounts issued are tracked by the TSO. GoOs of the second form can also be traded internationally, up to a specific amount. Other policy changes expected to take place are the reduction of feed-in tariff for wind energy, the prolongation of TGC scheme up to 2030, an increase in the goal to 15 TWh for new production, and a shift of the obligation towards suppliers (RECS 2005).
} 
January 2007. Key modifications are as follows (Ministry of Sustainable Development 2006):

- Increased target and extended timeframe: A new ambition level of 17 TWh by 2016 compared to 2002 was set. Originally, the target aimed at $10 \mathrm{TWh}$ increase. The time frame will extend until 2030 , as compared to 2010. Thus, quota obligations adjusted accordingly

- Shift in parties subject to the quota obligation: Originally, end-use consumers were the obliged actors under the scheme. Electricity suppliers were responsible for meeting their customer's quota obligation unless end users did not opt to deal with their own RE obligation. Suppliers could charge end users for handling the certificates service that they provided. Currently, the responsibility for meeting the quota obligation is on electricity suppliers and the requirement to itemize the certificate on the electricity bill ended. Nevertheless, suppliers can still transfer compliance costs to end users

- New allocation period for certificates: Power plants are now entitled to gain certificates for a maximum period of 15 years, which means that plants entering into the scheme no later than 2016 are entitled to TGC up to the end of the scheme's period. Depending on the type of production, plants commissioned before 2003 will no longer entitled to gain TGC by the end of 2012-2014. Specific restrictions were introduced for smallscale hydropower

Table 3 presents design parameters and responsible bodies that participate in the Swedish TGC scheme.

\section{Lessons from the Dutch and Swedish TGC schemes}

In this section, we identify some criteria that are useful for a comparative evaluation of the examined TGC schemes and can lead us to conclusions on which factors are important for the design of a TWC scheme. More analytically, the criteria selected are cost effectiveness and trading, energy effectiveness, administrative burden, technological innovation, political feasibility, and transaction costs.
Cost effectiveness and trading

\section{The Netherlands}

As from January 2001 to January 2007, the Dutch green certificates scheme (currently transitioned to GoOs) has made use of more than 73 million certificates, where 45 million are domestically issued and the rest originate from imported production. Redeemed and expired certificates amount to 67 million, which leads to a current availability of fivesix million certificates in the market ${ }^{9}$.

In the same period, based on similar figures, the main contributor in domestic RE production was biomass (generating 15 million certificates), followed by wind energy (nine million certificates), and at a lesser extent water ( 0.5 million) and solar energy.

For the period 2000-2003, the subsidy for RE was higher than the costs of RE and there was fear of over subsidization, which resulted to artificially lower prices for consumers. There was no regulation for the information of consumers from distributors of RE. To this cause, authorities initiated some remedies in order to reduce the negative impacts of the scheme. Initially, the REB exemption reduced in 2002 and the production subsidy congested, while MEP supported only domestic RE production. In addition, labeling of RE production was suggested, in order for consumers to be aware of the origin of electricity.

The TGC did not increase the price for final consumers but a fixed price took place instead: $52 €$ per household yearly premium on energy bill, which represented the levy to finance the feed-in tariff. The other costs were included in the budget for marketing and did not finance the certificate system cost. TGC was vulnerable to price volatility and other exogenous changes, mainly from the level of feed-in tariff and the imported RE. The price of TGC was strongly affected from imported RE and was reduced to the level of $0.6 € \mathrm{ct} / \mathrm{kWh}$ (Agnolucci 2007).

Concerning the Dutch GoOs system, some problems identified are that MEP does not specify that the subsidized RE must be consumed domestically. This enables exports of GoOs to other countries that need to fulfil their target, but this also means that these GoOs will not count against the Dutch target after exporting them. Exports predefine that the value of

\footnotetext{
${ }^{9}$ Data originate from http://www.certiq.nl.
} 
Table 3 Key features of the Swedish tradable green certificates scheme
Swedish TGC scheme

\begin{tabular}{|c|c|}
\hline Obliged parties & Electricity suppliers undertake the target of electricity consumers \\
\hline Compliance period & $2002-2030$ \\
\hline Obligation & $17 \mathrm{TWh}$ \\
\hline Reference & Domestic production \\
\hline Criteria & Quota increased yearly \\
\hline Eligible technologies & $\begin{array}{l}\text { Wind, solar, geothermal, biofuels, wave, hydro (smaller, existing and } \\
\text { new plants) }\end{array}$ \\
\hline Project evaluation & Monthly statements of generators \\
\hline Certificates & $\begin{array}{l}\text { Green certificates (Elcert; redeemed at a guaranteed price and unlimited } \\
\text { time valid) and parallel GoOs (tradable and nontradable) }\end{array}$ \\
\hline Trading parties & Energy producers and suppliers (including bilateral agreements) brokers \\
\hline Penalty & $150 \%$ of the average certificate price of the previous period \\
\hline Scheme financing & $\mathrm{n} / \mathrm{a}$ \\
\hline Banking & $\begin{array}{l}\text { TGC in this scheme can be banked and used in the following trading } \\
\text { periods, accounting for the targets. Certificates are issued and } \\
\text { allocated monthly by the Swedish National Grid in an electronic } \\
\text { registered form }\end{array}$ \\
\hline Total system costs & $\mathrm{n} / \mathrm{a}$ \\
\hline Targets achieved & $\begin{array}{l}\text { 77\% by April 2004; 99\% by April 2005; 99\% by April 2006; 98\% } \\
\text { by April } 2007\end{array}$ \\
\hline Issuing body & $\begin{array}{l}\text { Swedish National Grid Company (Svenska Kraftnät). TGC are issued } \\
\text { monthly and credited to the RE generators. TGC exist only in a virtual } \\
\text { form }\end{array}$ \\
\hline Monitoring & $\begin{array}{l}\text { The Swedish Energy Agency monitors the scheme's compliance as well } \\
\text { as developments on the TGC market. The Agency decides on penalty } \\
\text { charges for those who have not submitted a declaration by 1st March. } \\
\text { In addition, it sets the quota liability charges if quota liabilities are not } \\
\text { fulfilled }\end{array}$ \\
\hline Verification & $\begin{array}{l}\mathrm{RE} \text { producers receive one certificate for each MWh of qualifying } \\
\text { production from an approved plant. The number of certificates issued } \\
\text { depends on the reported metered production }\end{array}$ \\
\hline Registration & $\begin{array}{l}\text { The Swedish Energy Agency has to approve an electricity production } \\
\text { facility. The facility must connect to an electricity grid, and production } \\
\text { must be metered on an hourly basis. Svenska Kraftnät is responsible } \\
\text { for establishing and maintaining the register of certificate accounts. A } \\
\text { fee from the account-holder covers related administrative costs of } \\
\text { operating the register }\end{array}$ \\
\hline Redemption & $\begin{array}{l}\text { No later than March 31st, obliged parties must show that they sufficient } \\
\text { certificates in their accounts in order to meet their quota liabilities. The } \\
\text { Swedish Energy Agency is responsible for processing these } \\
\text { declarations. Svenska Kraftnät cancels TGC on April 1st based on } \\
\text { submitted TGC for quota fulfillment }\end{array}$ \\
\hline
\end{tabular}

Dutch GoOs abroad is higher than the REB; nevertheless, this could jeopardize the fulfillment of the Dutch target. The market price of certificates remained at a low level, since the import of GoOs and a feed-in tariff subsidized the production. Unfortunately, there are no publications available on the breakdown of information, transaction, and administrative costs, but the size of the Netherlands and a small number of players do not render them significant $^{10}$. Some indicative values since 2005 demonstrate that the price of a GoO lies between the range of 20-25 €ct/MWh and is expected to remain in the same level, unless if certificate schemes are harmonized and integrated (Voogt et al. 2006).

\footnotetext{
${ }^{10}$ Personal communication with Niermeijer (2005).
} 


\section{Sweden}

The usage of biofuels heavily dominated the issuance of TGC and, thus, RE production (see Fig. 1). Until April 2007, more than 44 million of certificates were issued in Sweden. Since the introduction of the scheme, issued TGC originated predominantly from electricity through biofuels (75\%), followed by hydropower (17\%), and at a much lesser extent wind energy (8\%), while solar energy has had a rather marginal contribution.

During 2003, there was a rapid escalation of TGC prices, ranging from 17.6 to $26.4 €$ per certificate (one certificate $=1 \mathrm{MWh}$ ) and high volatility was observed. Prices reached a peak of $27.5-29.7 € / \mathrm{MWh}$ at the beginning of 2004 followed by a rapid fall to around $22 €$ in April-May 2004, due to the fact that market prices and penalty fee gave room for high speculation and noncompliance. Indicatively, the penalty was set to $150 \%$ of the weighted average price during 2003/ 2004, where it was capped at 19.25 and $26.4 €$ per certificate, respectively (Nilsson and Sundqvist 2007). Since 2005, market prices have been ranging between 19.8 and $24.2 € / \mathrm{MWh}$. For the latest quota period, average market price has been $20.4 €$ per certificate. Nevertheless, the lack of baseline does not allow us to ascertain whether trading has yielded cost savings.

Prior to the modification in January 2007, obliged parties (i.e., end users) did not have other option butto-buy TGC. Currently, electricity suppliers - that are responsible for meeting the quota obligation - have a mixed approach: buying TGC on the market or producing green electricity. Until April 2007, parties traded more than 65 million of TGC in the Swedish market. According to Svenska Kraftnät statistics, average market price of TGC was approximately 22 $€ / \mathrm{MWh}$ in $2004,23.8 € / \mathrm{MWh}$ in 2005 , and $21 € /$ MWh in 2006 (STEM 2007b). ${ }^{11}$ These average market prices are much higher than the ones forecasted prior to the implementation of the scheme, ranging between 5.5 and $17.6 €$ per TGC (SOU 2001, p. 77).

Trading of TGC has taken place mostly through brokers (40\%) and bilateral agreements (40\%) and at a lesser extent by open trades within obliged parties (20\%; Westrin 2007). Trading on the Nord Pool

\footnotetext{
${ }^{11}$ The conversion rate used is $1 €=9.19$ SEK (as on April 2007).
}

power exchange market has been insignificant. According to Nilsson and Sundqvist (2007), limited trades are observed because this is forward market and certificates need to be issued before traded.

Electricity prices for domestic end users have increased but the TGC scheme itself partly explains that (STEM 2007a) since 2003, certificates have accounted for around $2 \%$ of total electricity bill for domestic end users (STEM 2007a, p. 39; STEM 2005a, p. 32), which in absolute terms, means that the average price of TGC charged to end users has escalated from $0.27 € \mathrm{ct}$ per $\mathrm{kWh}$ in 2003 to $0.29 € \mathrm{ct}$ per $\mathrm{kWh}$ in 2006. Nevertheless, it is worth mentioning that these values seem much higher if one looks at the ones forecasted prior to the implementation of the scheme: Prices of TGC for electricity end users were estimated to range between 0.11 to $0.16 € \mathrm{ct}$ per $\mathrm{kWh}$ (SOU 2001, p. 77). Apart from the TGC scheme, other causes attributed to electricity price increases are: variable weather conditions (affecting hydro), increased in electricity tax increase (32\% since 2002$)$, rising price of fossil fuels, and the introduction of the European $\mathrm{CO}_{2}$ emission trading scheme (STEM 2007a, p. 40).

\section{Energy effectiveness}

\section{The Netherlands}

The Dutch green labels scheme did not reach almost $40 \%$ of the target (i.e., $700 \mathrm{GWh}$ ), due to the uncertainty of the role of imported RE (Agnolucci 2007). In the same period, openness to imports increased the latter one and led to speculation on labels' price. Finally, liberalization led to a duopolistic situation, where two large multi-utility companies dominated the market.

During the second period, Dutch TGC managed to achieve the targets set, by increasing the number of customers that purchased and used RE (in 2001 there were 250,000 customers while in 2003 they rose to 2.2 million, $32 \%$ of the households). Large advertising campaigns and no price differential assisted to this cause (Agnolucci 2007).

In addition to the RE deployment target, parallel targets were achieved. Consumers' awareness towards RE use increased and steps towards energy supply market liberalization are paved. Van Rooijen and van Wees (2006) mention that energy companies affiliated 
Fig. 1 Electricity certificate production per renewable energy source by the end of compliance period. Note that 'solar' had a marginal contribution (i.e. $<20 \mathrm{MWh}$ ) compared to the other sources during the analyzed period. Also note that peat, biogas, and landfill gas became eligible fuels for green certificates on April 1 2004. Data source: Svenska Kraftnät (2007)

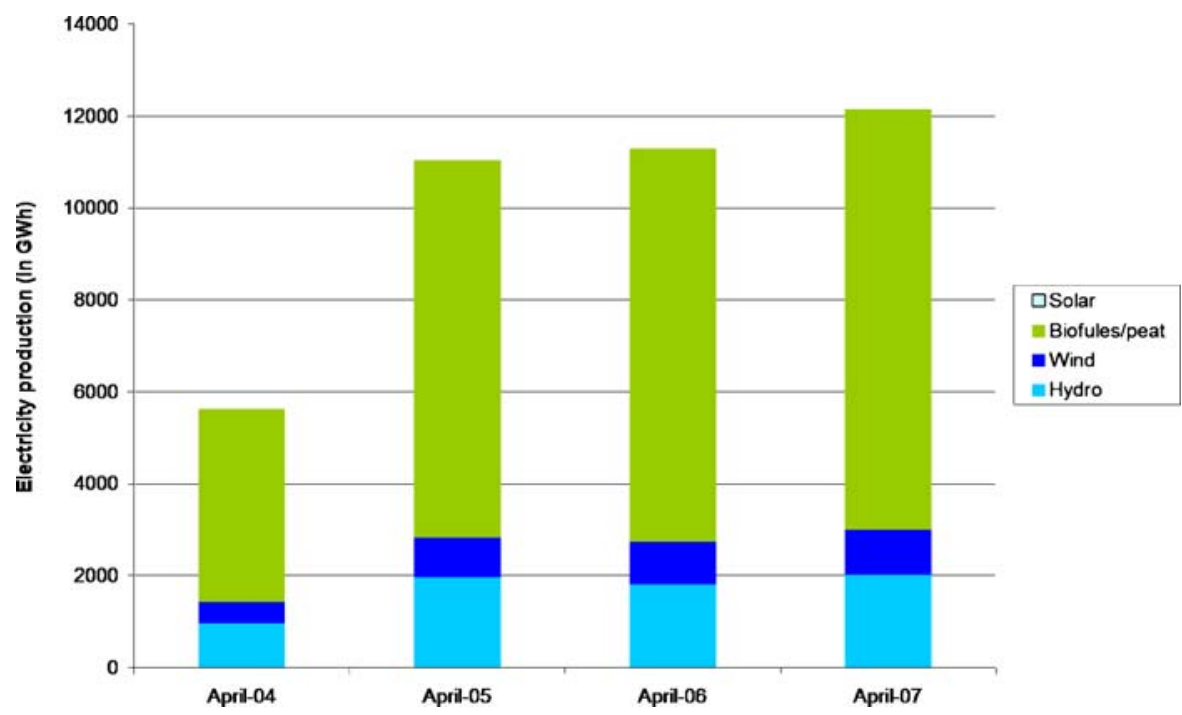

through the scheme with launching market campaigns and attracting more customers. The basic hurdle in the scheme was the lack of an actual market. The demand of TGC was either national (specific certificates, GC, $\mathrm{CHP}$ ) or international (with a huge supply and almost no demand).

During 2000-2003, imported RE counting against targets increased, which enforced foreign production with a factor of 6 , from 1.4 TWh in 2000 to $7.7 \mathrm{TWh}$ in 2001. Domestic production was not significantly stimulated, due to delays of licensing procedures and the insecurity for continuity of existing fiscal support mechanisms. Furthermore, the targets were inconsistent, in terms of consumption $(6 \%)$ or production $(17 \%)$.

TGC did not achieve the improvement of competitiveness domestically, but they increased the transparency towards consumers ${ }^{12}$. TGC policy could be characterized ineffective, also due to the fact that domestic supply did not increase, while imports covered the rising demand from small-scale consumers.

As far as the Dutch GoOs are concerned, energy effectiveness is also dependent on the additionality criteria, which refer to imported RE if the exporting country does not calculate sold electricity in its domestic target counting. In other words, additionality signifies that consumption of RE can lead to new power. Nevertheless, it is not yet possible to fulfil this criterion (RECS 2005). Another issue arising with GoOs is the double counting, where an exporting

\footnotetext{
${ }^{12}$ Personal communication with Niermeijer (2005).
}

country registers the green value of selling RE on its accounts, while the Netherlands registers the same value on its account based on the consumption of imported RE. Similar issue arises with the disclosure of GoOs, which provides uncertainty in the achievement of energy effectiveness.

\section{Sweden}

In 2005, the Swedish Energy Agency carried out an evaluation of the scheme's performance. Based on this, the agency (including many observers) feared that the scheme was going to fail to deliver the original energy target of $10 \mathrm{TWh}$ by 2010 . Investment conditions and political uncertainty around the future of the scheme after 2010 constrained the effectiveness of meeting the proposed energy target (STEM 2005b). For instance, policy uncertainty made utilities to postpone investments during the introduction and periodical abolition of subsidies (Nilsson et al. 2004; Wang 2006). The agency provided a set of recommendations - inter alia — stressing the need for a long-term quota obligation scheme. It was argued that the TGC scheme should be a permanent component of the Swedish energy policy and that ambition levels and quotas should remain for a period of 10 to 15 years. These conditions were considered crucial to reduce uncertainties about both the TGC market and the financial performance of RE by increasing the willingness to invest. Consequently, the scheme went through several design modifications in order to enhance the long-term perspective of the 
scheme-as suggested. Quota obligations were modified in order to reflect the new ambition level and longer time period (see Fig. 2).

Despite the fact that modifications took place only on January 2007, some stakeholders were confident about the implementation of these policy recommendations back in 2005. ${ }^{13}$ Early policy discussions started to send right signals to stakeholders and the effectiveness of the scheme in energy terms improved substantially (see Table 4). Still, uncertainties about the specific features of the modifications entailed high market risks for electricity suppliers (Nilsson and Sundqvist 2007). Nevertheless, the current situation based on policy modification is changing the field dramatically and more market confidence is present, given that a policy goal for Sweden is to become the first economy free from fossil fuels by 2020 .

By creating more favorable conditions for RE, TGC market, investments, and electricity production have been nearly sufficient to meet the new quota liabilities. In Table 4, after the first compliance period, the level of energy effectiveness has ranged between $97 \%$ and $99 \%$. This higher effectiveness accompanied lower average TGC market price (e.g., TGC price in 2006 is $12 \%$ to $17 \%$ lower than prices for 2005 and 2004, respectively). Nevertheless, if we consider as an indicator of the installed capacity per $€$ spent, the Swedish TGC has achieved relatively modest results in comparison to other countries (Wang 2006).

Administrative burden for the authority

\section{The Netherlands}

A main hurdle of the Dutch scheme was that the coverage of the target with imported RE was not preset, so there were no arrangements made in advance for the avoidance of double counting (van Rooijen and van Wees 2006). This problem eventually required extra procedures ex post that increased administrative costs. Some basic weaknesses of the scheme during the period 1998-2000 stemmed from interaction with consumers' voluntary schemes, where in order to avoid double counting, the administrative burden was high. Therefore, there

\footnotetext{
${ }^{13}$ Personal communication with Normand, Hedenström and Kåberger (2005).
}

was no clear distinction on electricity originated from labels.

During 2000-2003, monitoring and control responsibilities were attributed to a big number of bodies (MinEZ, DTe, TenneT, Belastingsdient), which resulted in malfunctioning of the scheme. Furthermore, the design phase did not include a high participation of different stakeholders, which could eventually minimize risks that came out after the implementation of the scheme.

Recent data from Certiq indicate that registration costs for an RE producer is $25 €$ initially and $25 €$ every year for participation. For aggregators, registration costs amount to $750 €$ with an equal amount paid every year. If transactions exceed 50,000 MWh at the end of a year, then an additional fee of $1,750 €$ is charged. Similar fees apply to traders (i.e., $750 €$ initially and $750 €$ yearly subscription) alongside with the same threshold charge (over 50,000 MWh transactions).

Furthermore, tariffs that sum up to the market price of a certificate are $0.062 € / \mathrm{MWh}$ for issuance payable by the party to whose account certificate are credited, $0.012 € / \mathrm{MWh}$ for all transactions payable by the purchaser, $0.062 € / \mathrm{MWh}$ for redemption payable by the traders, and $0.012 € / \mathrm{MWh}$ for imports. These costs do not exceed $1 \%$ or $2 \%$ of TGC price (Schneider 2005, p. communication). Due to the high volumes of TGC traded, an income surplus was created, redistributed as a rebate of $36 \%$ of transaction costs (Voogt et al. 2006).

As presented above, administrative costs for the authority in the Netherlands are not assumed being high, since financing for institutions originates from system users (in the form of fees) and from end users. This is the typical case in most countries so far, with the exception of the UK and Austria.

\section{Sweden}

The administrative costs in Sweden vary depending on the TGC certificate cycle. There is no fee concerning approval of RE facilities. There is neither registration nor issuing nor redemption fee. There is a fee of $0.55 € c t$ per transferred certificate (paid by the seller) and a penalty fee if obliged parties do not meet their quota obligation. In addition, there are other fees such as the 'Kontoavgift' (almost 3.3 €ct per certificate), which is calculated on the highest number 
Fig. 2 New quota obligation in the Swedish tradable green certificate scheme and resulting renewable electricity production (in TWh).

Data Source: STEM 2007a, b; Westrin 2007)

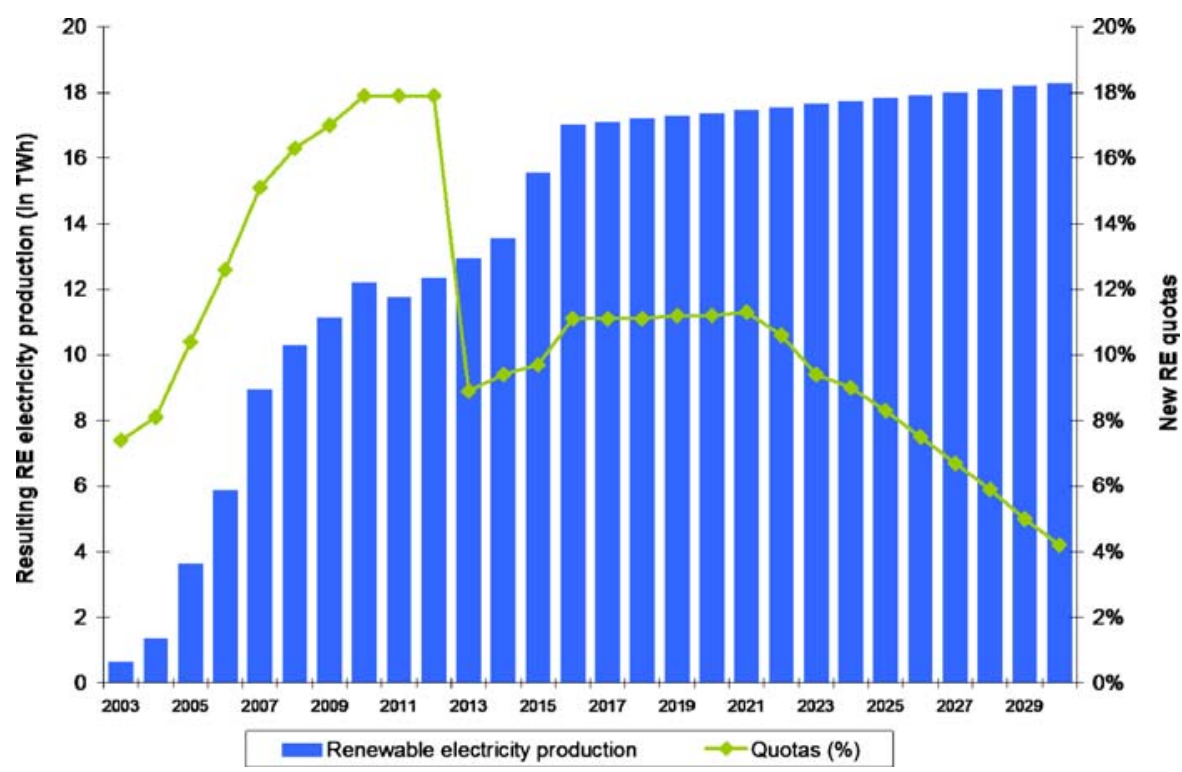

of certificates that a party has registered on the account the previous quarter. There is also an 'administrative fee' (11 €) applied if actors do not use Svenska Kraftnät's website system for administration or related issues. In addition, Svenska Kraftnät also has the possibility to charge all actors $22 €$ per year for using the website system. It is difficult to draw the line in terms of heavy or low administrative burden. Looking at the above figures, one can say that administrative burden is low; nevertheless, as Kåberger et al. (2004) argues, it is gradually increasing.

Technological innovation

\section{The Netherlands}

The Dutch TGC did not lead to domestic innovation or diffusion of new RE technologies; instead, the feed in tariff achieved this objective. A basic reason was the lack of time frame of many Dutch RE policies; therefore, uncertainty on the future of policies was present, which did not lead to investments in new technologies and plants. Moreover, GoOs did not address the issue of innovation as such, in contrast to feed-in tariffs that target at specific technologies.

\section{Sweden}

During the first year of implementation, there was almost no new capacity as an outcome of the scheme (Normand 2005; Kåberger et al. 2004). Thus, uncertainties about the future of TGC market after 2010 led to insufficient investments and most certificates originated from existing facilities. This was precisely one of the reasons why the original proposed target was unlikely to be met if no new capacity was encouraged.

Certainly, the Swedish TGC scheme aimed to promote investments in the least cost RE sources, targeting a broad range of technologies. However, this created a lockout for new technologies (e.g., wind and $\mathrm{PV}$ ) and urged towards increase in production from existing and already incumbent competitive sources

Table 4 Quota obligation and energy effectiveness in the Swedish tradable green certificate scheme

\begin{tabular}{lcccc}
\hline Compliance by & April 2004 & April 2005 & April 2006 & April 2007 \\
\hline Electricity use (in TWh) & 63.34 & 97.36 & 95.98 & 97.07 \\
Quota obligation (\%) & 7.4 & 8.1 & 10.4 & 12.6 \\
Quota obligation (in TGC) & $4,534,335$ & $7,892,330$ & $10,129,197$ & $12,402,184$ \\
TGC redeemed & $3,489,984$ & $7,832,352$ & $10,119,869$ & $12,124,111$ \\
Energy effectiveness (\%) & 77.0 & 99.2 & 99.9 & 97.8 \\
\hline
\end{tabular}

STEM (2007a, b), Westrin (2007) 
(i.e., biomass CHP; cf. Wang 2006). In fact, bioenergy CHP - already profitable with the carbon tax back in 2003 - had profited the most from the scheme (Kåberger et al. 2004). Since then, the scheme has been criticized for not supporting technological innovation, in particular the fields of solar and wind energy (Kåberger et al. 2004). By 2005, the Swedish Energy Agency concluded that the scheme was not an acceptable support mechanism for technical development, in particular for technologies not established or commercialized (STEM 2005b). The agency has stressed the need for long-term research and development (R\&D). Until now, more than 200 million SEK has been collected by the Government from penalties for noncompliance (STEM 2007a, p. 20). However, we found that this amount has not been directed to any specific R\&D program but to general state budget.

Political feasibility

\section{The Netherlands}

In the initial phase, green labels were an initiative from energy companies outside of the sphere of influence of relevant ministries, which made them easily acceptable. On the contrary, TGC was a government initiative, parallel to the Electricity Law, which set targets and created market opposition. The Dutch TGC lacked a binding RE target, which created a high market risk since price of certificates depended exclusively on the price of RE. Conflicts took place between the lower house and the government in the absence of a quantitative target and the uncertainty created from government's consent on relying on imported RE (Agnolucci 2007).

Concerning the GoOs system, the story is quite more complex. Political acceptability is slightly higher in this case, since GoOs resemble to Renewable Energy Certificate Systems (RECS), stimulated by companies. Opposition in this sense rose from the necessity of this instrument and its trade offs with feed-in tariffs. GoOs s can be also linked to voluntary markets (e.g., in the Netherlands and Flanders), to direct obligations in the form of disclosure (e.g., the Netherlands, Belgium, and Austria), and to target counting (which is not the case so far) ${ }^{14}$. The issue

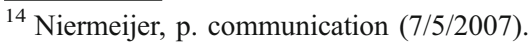

created opposition that originated from discussions on accepting GoOs and regarding them as separate from RE physical flow and on the future usage of GoOs (e.g., tradability).

\section{Sweden}

In Sweden, the TGC scheme faced a greater acceptability than other economic instruments. In fact, little political room exists today for feed-in tariffs, grants, and other financial instruments for encouraging RE (cf. STEM 2005a). The TGC replaced earlier policy instruments with a similar goal (STEM 2004). The Swedish TGC scheme did not require financing from the state budget (Westrin 2007). Since 1990, there have been various instruments used to support RE in Sweden. These included investment support for electricity production from biomass, wind energy and hydroelectric power, and an environmental bonus for electricity generated from wind power. ${ }^{15}$ However, looking at another economic instruments addressing wind power, one can easily observe the 'transition role' played by the scheme in financial terms. For instance, the TGC scheme complements, in principle, the so-called 'environmental subsidy' for wind power plants, which in 2005 gave 9 öre per $\mathrm{kWh}$ for onshore wind power and 16 öre per $\mathrm{kWh}$ for offshore wind production. Nonetheless, the 2004 Finance Bill determined to reduce progressively the environmental subsidy for both types of power production. For onshore production, the subsidy will be phased out completely by 2009 (STEM 2004).

Transaction costs

\section{The Netherlands}

Transaction costs (TCs) in a TGC scheme refer mainly to costs undertaken by obligated parties beyond costs of meeting the obligation itself. From a cost calculation conducted by Energieonderzoek Centrum Nederland (Battjes et al. 2000), such costs should be almost the same like regular transaction costs of a bank (around $2.5 \%$ of their total activity costs). Indicatively, for 2010 , TCs can be around

\footnotetext{
${ }^{15}$ There is also a special funding scheme for technical development and market introduction of large-scale wind power. This amounts for 350 million SEK over 5 years.
} 
$0.11 € \mathrm{ct} / \mathrm{kWh}$ while $22.7 € \mathrm{ct} / \mathrm{kWh}$ for $2020^{16}$. Table 5 presents some cost calculations with scenarios based on the aforementioned study.

\section{Sweden}

According to Kåberger et al. (2004), TCs hampered the early performance of Swedish TGC scheme, which were finally borne by electricity end users. According to the authors, around $18 \%$ of the total costs were accounted as TCs borne by users and profits made by electricity suppliers when transferring the costs to end users (see Table 6). While this estimate does not specifically address TCs as such but also profits, the authors argue that the burden of TCs is very likely to be greater for small electricity generators that handled the quota obligation on behalf of end users and usually lacked of full time staff devoted to administer the scheme at their organizational level.

Nilsson and Sundqvist (2007) demonstrate that the design of the Swedish TGC market was poor, which reduced its efficiency back in 2003. While their analysis does not confirm the hypothesis of TCs as a cause of high retail margins, the authors estimate that TCs represent an average price-cost margin between $15 \%$ and $24 \%$ over the period 2003-2005. A crucial source of TCs mentioned in this study refers to the administrative costs borne by suppliers handling the scheme.

As an outcome of early studies addressing the costs of the Swedish TGC scheme, evidence of overcharged customers was present. As mentioned before, the original design put the quota obligation on end users. At that time, electricity suppliers were allowed to charge their customers for handling the certificates service that they provided. However, when breaking down the figures (as shown in Table 6), it was found some rent-seeking behavior on behalf of electricity suppliers because a significant amount of money paid by electricity end users did not reach electricity producers (cf. Kåberger et al. 2004; STEM 2004). It remains to see how recent modifications to the scheme (e.g., abolishment of the certifi-

\footnotetext{
${ }^{16}$ These figures are calculated in this study based on the GCscenario (ECN) where energy demand is $3.7 \mathrm{EJ}$ in 2010 and 4.2 EJ in 2020. RE targets are hence $0.2 \mathrm{EJ}$ in 2010 (474 PJ) and $0.4 \mathrm{EJ}(640 \mathrm{PJ})$.
}

Table 5 Cost breakdown of Dutch tradable green certificates scheme

\begin{tabular}{lcc}
\hline Year & 2010 & 2020 \\
\hline Transaction costs $(€ \mathrm{ct}) / \mathrm{kWh}$ & 0.11 & 0.08 \\
Target $(\mathrm{TWh})$ & 11 & 30 \\
Governmental costs $(\mathrm{M} €) /$ year & 12.7 & 22.7 \\
Societal costs $(\mathrm{M} €)$ & 467 & 880 \\
System and transaction costs $(\mathrm{M} €)$ & 136 & 227 \\
End users costs $(\mathrm{M} €)$ & 732 & 1,206 \\
\hline
\end{tabular}

Battjes et al. (2000)

cate price on the electricity bill) will positively influence this aspect and reduce TCs. In any case, suppliers are still entitled to transfer the costs of certificates to end users. Now, the price of TGC is simply part of the electricity price so it eases the comparison of electricity costs for end users.

\section{Discussion}

In this section, we extract results drawn from our assessment of TGC schemes in the previous sections and we attempt to provide some recommendations to policy makers when they face various options of designing and implementing TWC systems. Some results from TGC schemes are sometimes contradictory among the Netherlands and Sweden; in that case, we transfer both experiences and do not provide sharp suggestions. Furthermore, within countries, different opinions and perceptions concerning the effects of TGC exist; therefore, it is not in our intention to demonstrate to the reader a normative aspect of designing TWC. Rather, we limit ourselves to a general framework of policy issues and highlight some experiences for each design phase that can trigger

Table 6 end user's costs and revenues of the Swedish tradable green certificates scheme as on 2003

\begin{tabular}{lcc}
\hline & öre per TGC & Share (\%) \\
\hline Average consumer costs & 32.3 & 100 \\
Of which VAT & 6.45 & 20 \\
Average TGC market price & 20.1 & 62 \\
Transaction costs and profits & 5.71 & 18 \\
\hline
\end{tabular}

Kåberger et al. 2004, p.687 
attention to the decision-making processes related to the design and implementation of TWC schemes.

Target setting and long-term policy conditions

At a first glance, the nature of targets of both instruments is somehow different, which can complicate the lessons drawn. TGC schemes aim at more 'environmental' targets, while TWC at 'energy effectiveness' ones, with some common targets on securing energy supply in the economy. The blending and hierarchy of targets can alter the functioning of both instruments; nevertheless, some basic traits of targets can provide us with some remarks. An obvious conclusion from TGC schemes is that a binding target has to be set from authorities in order to trigger the correspondent demand for increased energy efficiency (in the case of TWC), otherwise free-riding behavior from market parties or lack of incentives for implementing energy efficiency measures can prevail. Furthermore, this target must comprise a clear time frame of the policy instrument (see example of Sweden). This entails to provide the due certainty to market players about the political and stable market conditions in order to proceed with investments with a longer payback period and set necessary business strategies to cope with new policy demands.

Another aspect is that these targets must enhance the market liberalization process, otherwise reconsolidation tendencies and market dominance by few players will prevail. In addition, when defining a TWC target and providing longterm policy indications, policymakers should pay attention to whether the TWC market will be open or closed to other countries. The reason is that different rules should apply (for instance in the Netherlands imported RE with a not welldefined target, let to oversupply of certificates in the market with some consequences) and-if an international market takes place-harmonization with other schemes should be duly considered. In theory, an open market is optimal, but the design of parallel subsidization policies and incompatible schemes must be carefully taken into account.

Obliged parties

TWC obliged entities are in principle energy suppliers or energy distributors. Targets on each market player can also affect the amount of free riders of the policy. In addition, other market players should also get stimulated in order to participate voluntarily in the TWC scheme and invest in energy efficiency actions (for instance Energy Service Companies, ESCOs). Initially, domestic competition among energy suppliers and producers of energy efficiency goods should be pursued, so that the scheme maintains a dynamic effectiveness (which was not achieved in the Dutch TGC scheme). In general, ensuring a proper market requires that target groups consist of numerous actors with different market power, in order to avoid the risk of market dominance of very few players (i.e., oligopolistic market conditions).

From the Swedish TGC experience, it is worth noticing that obliged parties should be operationally close to sources that allow them to meet their target. As mentioned before, some electricity suppliers acted mostly as intermediaries between electricity generators and end users in the beginning of the scheme. This created conditions for rent-seeking behavior on behalf of suppliers, which increased the compliance costs for end users unnecessarily. This is the case of the Italian TWC scheme, where energy distributors do not have direct access to end users (International Energy Agency 2006). In this case, ESCOs and other intermediaries bring costeffective measures and are driven by the size of cost recovery, demonstrating rent-seeking behavior. This adds compliance costs to the scheme - and eventually to end users-who receive energy saving measures implemented through intermediaries.

\section{Counting rules}

Counting rules for energy savings are quite different from those of a TGC scheme, reflecting the underlying technical difficulties between energy efficiency and RE targets, respectively. TWC schemes employ a baseline and credit system that accredits energy savings, ex ante or ex post, based on a business as usual scenario of autonomous energy efficiency improvement. In principle, such scheme should entail clear procedures upon how reference scenariosincluding their updating process - are developed and how the savings calculated. To this extent, standardized common procedures should be employed for energy savings calculations (International Energy Agency 2006; EC 2006a). Finally, another parameter 
that could simplify verification procedures is the allowance of bundling (pooling) of projects from various implementers, which in practice can reduce the individual transaction and administrative costs of smaller projects and aggregate them with larger ones.

One core issue is the additionality demonstration (i.e., energy savings eligible for certification if realised on top of autonomous efficiency), which can create administrative bottlenecks and increased costs. This requirement does not exist in TGC schemes, but it is crucial in TWC schemes. As a criterion, it should not be technically but politically complex as such. In addition, it should focus more on the double-counting issue, which refers to accrediting twice energy savings that originate from other policy instruments (e.g., through voluntary agreements for energy efficiency). Furthermore, TWC schemes should incorporate/integrate eventually the counting rules triggered by the Directive on energy performance on buildings (EC 2002) and labeling of energy appliances (EC 1992).

\section{Compliance costs}

A core issue in designing TWC schemes refers to all involved costs that should not jeopardize the market functioning and cost-effective measures. Experiences from TGC schemes revealed that a quota with a certificate market can be cost-effective for numerous reasons, without necessarily depending on the certificate market as such. For instance, TWC prices can be low due to other subsidization policies for energy efficiency, which do not reflect in this case the true costs of such projects. A basic determinant on where the policy instrument should be applied is the price difference between different target groups (eligible end-use sectors) when implementing energy efficiency projects.

Financing RE in TGC schemes is substantially different from financing energy efficiency actions in a TWC scheme. Nevertheless, same as in TGC schemes, there should be a differentiation of stimulation for production of various energy efficiency goods. The most important parameter in this scheme, in order to keep compliance costs low beyond the existence of cheap energy efficiency options, is that market conditions should be met that can guarantee cost-effective energy savings. To this respect, an important market provision should facilitate trading of certificates and increase liquidity so that a saving target is met cost effectively.

\section{Transaction costs}

For both TGC and TWC schemes, main cost components are compliance and TCs. TGC experience showed that monitoring and verification costs are quite low, since they involve meter reading and auditing; therefore, energy suppliers can incorporate them in their normal activities. From a TC perspective, if an instrument parallel to investment risk raises TCs, supplier's profits must be higher than the cost of the equipment for an investment to be financially attractive. In this way, certificates (if linked to the bidding system with a tight cost cap) are quite unfavorable to the realization of plants because of insufficient payments or high volatility (Finon and Perez 2007), as opposed to the case of feed-in tariffs for the case of RE.

The issue of TCs is often a drawback of TWC schemes. They can be high enough especially during the initial planning and implementation period of eligible measures, before both the TWC trading and learning curves take into effect (Mundaca 2007). TWC schemes should be designed in such a way that market players can make use of their experience and know-how of implementing energy efficiency projects (for instance through involving Energy Performance Advice in the Netherlands), in order to keep such costs low. Mundaca (2007) provides some suggestions to this respect, for instance, standardized full cost accounting systems, ex ante monitoring and verification of energy savings, streamlined procedures, and standardized trading contracts could reduce such costs.

\section{Administration costs}

An important issue in the TWC scheme is that administrative costs (fees required for authorities' services in the scheme, e.g., for issuance, redemption) should be clear (standard flat fee) from the initiation of the scheme and not increasing over time, otherwise political uncertainty over costs can thwart profitable investments. Furthermore, not all procedures should take in administrative costs but rather those that address market effects (e.g., in Swedish TGC the 
Kontoafgift can be useful in terms of overconcentration of TGC by some companies and enhance market liquidity).

As identified in the Swedish TGC schemes, rentseeking behavior on behalf of electricity suppliers ended up with end users being overcharged (marginally compared to the overall electricity costs, though). End users can carry over the whole costs of energy efficiency projects but only under the precondition that they extract financial benefits out of their investment, otherwise risk for windfall profits from energy suppliers exists.

\section{Eligible technologies}

Similar to TGC, TWC schemes should be technology neutral, so that they can create competition among different technologies and avoid lock-in/out market situations (Nilsson and Sundqvist 2007). The number and kinds of eligible technologies addressed in a TWC scheme is crucial for its success in achieving the target at least possible costs. The number of technologies is also theoretically beneficial, but it does not guarantee by itself innovative (in particular more R\&D) outcomes. In fact, another objective of a TWC scheme-albeit not explicitly mentionedshould be the innovation of energy efficiency technologies and their market diffusion. This signifies that the target should not address only 'low hanging fruits' that could also be diffused in the market without an extra policy. Innovative technologies could be stimulated parallel to TWC through modifying existing instruments in a fair way so that 'difficult' energy efficiency products can be also encouraged (e.g., 'smart' subsidies that refer to phasing out of subsidies or deposit refund schemes that address already mature technologies and their balanced substitution to innovative energy efficiency technologies). From TGC, we learnt that whenever this was not the case, only incumbent technologies - already profitable as for bioenergy and $\mathrm{CHP}$-dominated the TGC market. Furthermore, one has to consider that while a higher number of eligible technologies is financially desired, trade offs exist because of higher M\&V efforts associated with them (Mundaca and Neij 2006). Furthermore, if there are combined technologies, e.g., biomass and CHP, they cannot be easily certified if there are different monitoring and verification rules per technology.
Institutional setup

Based on TGC experiences, when many administrative bodies undertake several procedures in the scheme, this can lead to a malfunctioning and subsequently increase in administrative costs. The same rule holds for TWC; therefore, few public bodies should undertake procedures that can cooperate from the issuing up to redemption phase of TWC. An increased number of procedures can also lead to postponing energy efficiency actions, since utilities can delay investments and their reduce profitability. As discussed above, core procedures is the monitoring, verification, and redemption of TWC (or energy savings as such as in Britain), where their rules should be crystal clear in order for the scheme to function properly. Another technical aspect for efficient TWC trading requires transparent exchange platforms with online information on prices and quantities of TWC traded (see Swedish TGC scheme). Finally, in the initial planning phase of a TWC scheme, discussions with relevant stakeholders in energy field are crucial in order to ensure public acceptance and retrieve necessary information for setting correct rules. In addition, other private and/or public bodies can play a significant role supporting awareness rising among end users.

\section{Trading rules}

Trading rules are crucial and determinant in certificate schemes. TGC experiences reveal that where trading rules were easy and not complicated, trading activity was present, which led to lowering of costs ${ }^{17}$. Trading rules should specify ways of dealing with both bilateral and open certificate exchanges. After distributing obligations clearly to market players, a proper design of TWC should comprise also mechanisms (e.g., financial incentives) that can stimulate both demand and supply of certificates on the market, without hampering trading activity. Based on Swedish TGC experiences with bilateral anonymous trades, a guarantee price on redemption of certificates can also

\footnotetext{
${ }^{17}$ Still on the voluntary markets, trading of TGC was quite small, and on the international market was mainly due to financial incentives (so marketing reasons could not guarantee trading) (Voogt et al. 2006).
} 
guarantee a market for energy suppliers. Such a feedin tariff can prove to be very useful in the beginning of a TWC, where uncertainties and trading dilemmas are dominant, but eventually could send wrong price signals in the long run (i.e., suppliers expect a price in the end of certificate period, which deters them from implementing more expensive and effective projects). Tradability of certificates depends also on the compliance/redemption period, lifetime of certificates, banking, and borrowing rules. Most certificate trading takes place on an annual basis, while their lifetime differs. In general, more frequent compliance periods, due to their market activity effects, and longer lifetimes of certificates, due to more price stabilization, could be preferable options. Furthermore, development of forward markets for TWC alongside with parallel financial products can enhance TWC trading (Voogt et al. 2006). Lemming (2003) presents a detailed analysis of the necessity of forward contracts and risk premiums in TGC markets. Similar to TGC, in order for suppliers to cover their costs, they can make use of forward contracts traded at a risk premium in TWC markets, which practically signifies that forward prices can be higher than expected TWC spot prices. Finally, banking and borrowing allows greater market liquidity, since demand and market forces can provide equilibrium in each subsequent period, but a concentration of certificates in some companies (due to their size and banking) could trigger TWC prices unjustifiably high, sending hence wrong market signals.

\section{Penalty}

Enforcement in certificate schemes can take different forms (e.g., financial penalties fixed or relative to market parameters) and policy views on this matter are quite controversial. From the Swedish TGC experience, penalties are set based on average market price of certificates during the previous trading period. While such an option can attain its objective, it jeopardizes speculation on price differential of the actual certificate price with the penalty, since both are intertwined and mutually dependant. Given that penalties act as a ceiling price to TWC price, they must ensure a clear market signal; therefore, they should not be low (or competitive to certificate prices) otherwise almost no incentives for energy efficiency actions are present. A stringent penalty can guarantee energy efficiency projects, but there is higher political acceptability risk. In all cases, a concrete penalty should be set and publicly known before the implementation of a TWC scheme, in order to provide correct market signals in advance and let suppliers decide on their investments. If necessary, the penalty (and related enforcement) should be updated accordingly.

\section{Links to other instruments}

A final issue that determines the overall effectiveness and efficiency of a TWC is its interactions with existing or planned policy instruments. In this paper, we do not deal in depth with interactions of policy instruments due to the complexity of the issue and the scope of this paper, but we merely refer to some obvious results. More specifically, based on TGC experiences, financial instruments at place during the same period have influenced the overall performance of TGC in the Netherlands and Sweden. These instruments were mainly tax deductions, subsidies for specific RE technologies and sources, and feed-in tariffs for RE production and supply. For the case of TWC, similar policy instruments can have positive or negative effects based on their design and parallel implementation (e.g., tax credits for eligible technologies in the French TWC scheme). Other market mechanisms that directly or indirectly interact with TWC are CHP certificates and TGC. The latter one should be considered very important, since there could be technologies that are eligible for certification in all these instruments (e.g., micro CHP and fuel switching), which can lead to double counting and, hence, ineffective allocation of resources. To this respect, eligibility should be preferably completely separate, either at technology or size level (e.g., large CHP are subject to TGC while micro CHP can be subject to TWC). As far as financial instruments are concerned, there is a potential danger when various subsidies for energy efficiency are applied, since some technologies can unnecessarily be more stimulated and, hence, innovation effects hampered. Subsidies should address specific technologies with market potential that may require large upfront costs and cannot enter the market due to 'low hanging fruits'. Furthermore, taxes on energy use can indirectly act as ceiling prices for TWC, but their effects can be quite uncertain (with financial thresholds because profitability with or without the extra incen- 
tive given by TWC), since an increased electricity price cannot by itself stimulate energy efficiency (other market barriers are quite important). Information campaigns also supported TGC schemes, which can be deemed quite necessary also for TWC, since they can increase public environmental awareness and stimulate consumers towards energy saving actions. Finally, a TWC scheme should broadly use labeling of energy efficiency products and deposit refund schemes ${ }^{18}$ because they can overcome knowledge and other nontechnical barriers. Some studies have dealt with the issue of interactions of TWC with other policy instruments, where more concrete lessons are to be drawn (Bertoldi et al. 2005; Farinelli et al. 2005; Harrisson et al. 2005; Oikonomou et al. 2007b; Oikonomou and van der Gaast 2008).

\section{Conclusions}

In this paper, we analyzed the experiences gained from Dutch and Swedish TGC schemes and extracted some policy lessons that can support a successful design of TWC. TGC schemes differ in terms of design and obligated parties, which renders them interesting in terms of lessons learnt. We conducted a general ex ante assessment for both TGC schemes on the grounds of the following evaluation criteria: cost effectiveness and trading, energy effectiveness, administrative burden, technological innovation, political feasibility, and transaction costs.

In the Netherlands, the TGC scheme under its different phases (former green labels now GoOs) has proved to be quite cost effective. The low cost was also a result of modifications of subsidies, tax exemptions, and feed-in tariffs functioning parallel in the market. Targets were achieved, although they can be considered inconsistent in the long run, since they referred to production and consumption, and the role of imported RE was unclear up to lately. A hurdle to innovation was the acceptance of imported RE, since domestic production was not stimulated and TGC supply was based on imported RE. Administrative burden was not high for the government, since

\footnotetext{
${ }^{18}$ See for instance the 'Market penetration strategy for energy efficient appliances' in the Netherlands (source: http://www.iea. org/textbase/pamsdb/detail.aspx? mode=pm\&id=2557).
}

fees pass over to system users. The main burden was the monitoring for double counting, as from imported RE and RE from voluntary schemes. Furthermore, transaction costs for utilities are not high enough to influence market behavior. Finally, the whole scheme was politically accepted when companies undertook the role (as in green labels), while some opposition rose under TGC in terms of its necessity towards existing feed-in tariffs (i.e., because of more stable or less volatile financial conditions for project developers).

Swedish TGC were cost effective in the sense that certificate prices are lower than predicted and the impact on consumer prices was limited. However, the lack of a baseline does not allow estimating costs savings from trading. Investment conditions and political uncertainty around the future of the scheme after 2010 constrained - at the early stage of the scheme-the energy effectiveness of the proposed energy target. Nevertheless, policy modifications took place and investments and electricity production are in the right direction to meet new quota liabilities. The scheme was not considered as acceptable support mechanism for technical development as well as for RE that were not established or commercialized.

Transaction costs were relatively high in the Dutch TGC and referred to administrative costs borne by suppliers to handle the scheme. In Sweden, the TGC scheme faced a greater acceptability than other economic instruments. In fact, little political room exists today for feed-in tariffs, grants, and other financial instruments for encouraging RE.

Taking into account the experiences gained so far by TGC schemes in the Netherlands and Sweden, we have identified some crucial policy lessons that policy makers should take into account when designing similar schemes for energy efficiency (i.e., TWC schemes). Our analysis indicates some policy suggestions for each specific design characteristic decided by policymakers in a TWC scheme. Highlighting the main points, the following recommendations can be drawn:

- A binding long-term target must be clearly expressed in terms of the TWC policy timeframe-reducing regulatory uncertainties for market actors

- A proper market must be ensured that requires that target groups should consist of numerous actors (e.g., avoid oligopolistic market conditions, increase liquidity, etc.) 
- Standardized common procedures should be employed for energy savings calculations (e.g., baseline setting, "deadweight", etc.)

- In order to keep compliance costs low beyond the existence of cost-effective energy efficiency options is that market conditions should be met that can guarantee the tradability of TWC

- Transparent and fair cost-recovery mechanisms targeting end users and effective enforcement by the authorities are crucial

- Standardized full cost accounting systems, ex ante monitoring and verification of energy savings, streamlined procedures, and standardized trading contracts must be employed in order to reduce transaction costs

- TWC schemes should be technology neutral, so that they can create competition among different energy efficiency technologies and avoid lock-in/ out market situations

- The energy efficiency target should not address only the 'low hanging fruits' that could also be diffused in the market without an extra policy. Innovative technologies can be also stimulated parallel to TWC through modifying existing instruments; however, clear definition about additionality is required

- A concrete penalty should be set and publicly known before the implementation of a TWC scheme, in order to provide in advance correct market signals and let obliged parties develop their investments plans and further market strategies

Acknowledgements The authors would like to thank $\mathrm{P}$. Niermeijer, C. Hedenström (RECS International), H. Schneider (CEA, the Netherlands), M. Normand (STEM, Sweden), and T. Kåberger (IIIEE, Sweden) for their valuable comments on the green certificate schemes in the Netherlands and Sweden, respectively.

Open Access This article is distributed under the terms of the Creative Commons Attribution Noncommercial License which permits any noncommercial use, distribution, and reproduction in any medium, provided the original author(s) and source are credited.

\section{References}

Agnolucci, P. (2007). Renewable electricity policies in the Netherlands. Renewable Energy, 32(5), 868-883.

Battjes, J. J., Beeldman, M., Jansen, J. C., Kroon, P., Ormel, F. T., Schaeffer, G., et al. (2000). Beleidsopties voor CO2emissiereductie en de inzet van hernieuwbare energie in een geliberaliseerde energiemarkt. ECN Beleidsstudies, ECN-C-00-048, the Netherlands.

Bertoldi, P., \& Rezessy, S. (2006). Tradable certificates for energy savings (white certificates). Brussels: European Commission Joint Research Centre.

Bertoldi, P., Rezessy, S., Langniss, O., \& Voogt, M. (2005). White, green and brown certificates: how to make the most of them?. Brussels: European Commission Joint Research Centre.

Dijk, A. L. v., Beurskens, L. W. M., Boots, M. G., Kaal, M. B. T., Lange, T. J. D., Sambeek, E. J. W. v., et al. (2003). Renewable energy policies and market developments. the Netherlands: ECN Beleidsstudies.

EC (1992). Directive 92/75/EEC of the EU Parliament and the Council of 22/91992 on the indication by labelling and standard product information of the consumption of energy and other resources by household appliances. Brussels.

EC (2001). Directive 2001/77/EC of the EU Parliament and the Council of $27 / 9 / 2001$ on the promotion of electricity produced from renewable energy sources in the internal electricity market. Brussels.

EC (2002). Directive 2002/91/EC of the EU Parliament and the Council of $4 / 1 / 2003$ on the energy performance of buildings. Brussels.

EC (2006a). Directive 2006/32/EC of the EU Parliament and of the Council of 27/4/2006 on energy end-use efficiency and energy services and repealing Council Directive 93/76/ EEC. Brussels.

EC (2006b). Action plan for energy efficiency: realising the potential. COM (2006) 545 final. Brussels.

Farinelli, U., Johansson, T., McCormick, K., Mundaca, L., Oikonomou, V., Örtenvik, M., et al. (2005). "White and Green": comparison of market-based instruments to promote energy efficiency. Journal of Cleaner Production, 13(10-11), 1015-1026.

Finon, D., \& Perez, Y. (2007). The social efficiency of instruments of promotion of renewable energies: a transactioncost perspective. Ecological Economics, 62(1), 77-92.

Harrisson, D., Sorrell, S., Radov, D., Klenvas, P., \& Foss, A. (2005). Interactions of the EU ETS with green and white certificate schemes. London: NERA Economic Consulting.

International Energy Agency (2006). Market mechanisms for white certificates trading - task XIV final report. In A. Capozza (Ed.), Implementing agreement on demand-side management technologies and programmes. Milano, Italy: CESI Ricerca.

Kåberger, T., Sterner, T., Zamanian, M., \& Jürgensen, A. (2004). Economic efficiency of compulsory green electricity quotas in Sweden. Energy \& Environment, 15(4), 675-697.

Kraftnät, S. (2007). Market information about the electricity certificate system. Available [online] at https://elcertifikat. svk.se.

Langniss, O., \& Praetorius, B. (2006). How much market do market-based instruments create? An analysis for the case of "white" certificates. Energy Policy, 34(2), 200-211.

Lemming, J. (2003). Financial risks for green electricity investors and producers in a tradable green certificate market. Energy Policy, 31, 21-32.

Ministry of Sustainable Development (2006). Renewable electricity with green certificates. Government Bill 2005/ 
06:154. Retrieved April, 20, 2007, from http://www. sweden.gov.se/content/1/c6/06/47/22/2c000830.pdf.

Mitchell, C., \& Anderson, T. (2000). The implications of tradable green certificates for the UK. (UK: SPRU).

Mundaca, L. (2007). Transaction costs of tradable white certificate schemes: the energy efficiency commitment as case study. Energy Policy, 35(8), 4332-4339.

Mundaca, L., \& Neij, L. (2006). Transaction costs of energy efficiency projects: a review of quantitative estimations. EuroWhiteCert project (http://www.eurowhitecert.org). Contribution to Work Package 3. (Lund: IIIEE).

Mundaca, L., \& Santi, F. (2004). Quantitative assessment of selected policy instruments using the Western European MARKAL model. Phase III of the EU SAVE "White and Green" project (http://www.iiiee.lu.se/whiteandgreen). (Lund: IIIEE).

Nilsson, L., Johansson, B., Astrand, K., Ericsson, K., Svenningsson, P., Borjesson, P., et al. (2004). Seeing the wood for the trees: 25 years of renewable energy policy in Sweden. Sweden: Energy for Sustainable Development.

Nilsson, M., \& Sundqvist, T. (2007). Using the market at a cost: how the introduction of green certificates in Sweden led to market inefficiencies. Utilities Policy, 15(1), 49-59.

Normand, M. (2005, June). Introduction to and first experiences of Green electricity Certificates in Sweden (powerpoint presentation in workshop on 'National or International Systems for White Certificates - what can we learn from tradable green certificates?', Lund).

Oikonomou, V., \& Jepma, C. J. (2008). A framework on interactions of energy and climate policy instruments. Journal of Mitigation and Adaptation Strategies for Global Change, 13(2), 131-156.

Oikonomou, V., \& van der Gaast, W. (2008). Integrating Joint Implementation projects for energy efficiency on the built environment with white certificates in the Netherlands. Journal of Mitigation and Adaptation Strategies for Global Change, 13(1), 61-85.

Oikonomou, V., Becchis, F., \& Russolillo, D. (2007a). White certificates for energy efficiency improvement with energy taxes: a theoretical economic model. ECEEE 2007 Summer Study Proceedings, Saving Energy_-Just Do It!, Cote d' Azur, France.

Oikonomou, V., Rietbergen, M., \& Patel, M. (2007b). An ex-ante evaluation of a white certificates scheme in the Netherlands: a case study for the household sector. Energy Policy, 35(2), $1147-1163$.

Oikonomou, V., Zevgolis, D., \& Grafakos, S. (2008). Methods of integrating policy instruments. Energy and Climate Policy Interactions (ECPI) Decision Support Tool. EDREC Discussion Paper, Groningen.

Portney, P. R. (2003). Market-based approaches to environmental policy: a "Refresher" course. Resources for the future, 151, 15-18.

RECS (2005). The use of the Guarantee of Origin. Utrecht: RECS International.
Schaeffer, G., Boots, M., Mitchell, C., Timpe, C., Cames, M., \& Anderson, T. (2000). The implication of green certificates for the deployment of renewable energy. the Netherlands: ECN Beleidsstudies.

SOU (2001). Handel med elcertifikat—ett nytt sätt att främja el från förnybara energikällor. Retrieved November 10, 2005, from http://www.regeringen.se/content/1/c4/22/16/ f784596e.pdf.

STEM (2004). Renewable electricity is the future's electricity. Retrieved August 9, 2005, from http://www.stem.se/web/ biblshop_eng.nsf/FilAtkomst/ET26_04.pdf/\$FILE/ ET26 04.pdf?OpenElement.

STEM (2005a). Energy in Sweden 2005. Retrieved January 20, 2005, from http://www.energimyndigheten.se/web/biblshop. nsf/FilAtkomst/ET2005_25w.pdf/\$FILE/ET2005_25w.pdf? OpenElement.

STEM (2005b). Permanent electricity certificate system. Press release June 2005. Retrieved August 9, 2005, from http:// www.energimyndigheten.se/WEB/STEMEx01Eng.nsf/ PageGenerator01? OpenAgent \&MenuSelect $=7238$ C01AAC636561C1256EFD003A96DA\&FuncArt Select $=$ C6B07CA4BB11AAECC1256F4800535A04\& FuncParm $1=1 \&$ FuncParm $2=2$.

STEM (2005c). Energy in Sweden 2004. Retrieved May 20, 2005, from http://www.stem.se/web/biblshop_eng.nsf/FilAtkomst/ ET19_04.pdf/\$FILE/ET19_04.pdf?OpenElement.

STEM (2007a). Energy in Sweden 2006. Retrieved March 10, 2007, from http://www.energimyndigheten.se/web/biblshop_eng. nsf/FilAtkomst/ET2006_45.pdf/\$FILE/ET2006_45.pdf? OpenElement.

STEM (2007b). The electricity certificate system. Retrieved April 20, 2007, from http://www.energimyndigheten.se/.

STEM \& Swedish EPA (2004). Swedish Climate Strategy. Retrieved August 12, 2005, from http://www.stem.se/web/ biblshop_eng.nsf/FilAtkomst/ET33_04.pdf/\$FILE/ ET33_04.pdf?OpenElement.

van Alphe-n, M., \& Pfeiffer, E. A. (2005). SETREC Report on (actual and projected) TREC trade and side-effects in the Netherlands. EU SETREC-GO project Phase II (http:// www.re-go.info/setrec.html).

van Rooijen, S. N. M., \& van Wees, M. T. (2006). Green electricity policies in the Netherlands: an analysis of policy decisions. Energy Policy, 34(1), 60-71.

van Sambeek, E. J. W., \& van Thuijl, E. (2003). The Dutch renewable electricity market in 2003. An overview and evaluation of current changes in renewable electricity policy in the Netherlands. the Netherlands: ECN Beleidsstudies.

Voogt, M., Luttmer, M., \& de Visser, E. (2006). Review and analysis of national and regional certificate schemes. EuroWhiteCert project Work Package 2 (http://www.euro whitecert.org). (Utrecht: ECOFYS).

Wang, Y. (2006). Renewable electricity in Sweden: an analysis of policy and regulations. Energy Policy, 34(10), 1209-1220.

Westrin, M. (2007). The Swedish electricity certificate system (powerpoint presentation). Unpublished. Brussels, April. 